\title{
Beneficial Uses of Radiation
}

Prepared for the U.S. Department of Energy

Office of Environmental Restoration and

Waste Management

\author{
(29) Westinghouse \\ W. Hanford Company Richland, Washington
}

Hanford Operations and Engineering Contractor for the

U.S. Department of Energy under Contract DE-AC06.87RL10930

Copyright License By accoplance of this article, the publisher and/or recipient acknowledgos the U.S. Government's right to retain a nonexclusive, royalty-tree liconse in and to any onpyright covering this paper. 


\section{LEGAL DISCLAIMER}

This report was prepared as an account of work sponsored by an agency of the United States Government. Neither the United States Government nor any agency thereof, nor any of their employees, nor any of their contractors, subcontractors or their employees, makes any warranty, express or implied, or assumes any legal liability or responsibility for the accuracy, completeness, or any third party's use or the results of such use of any information, apparatus, product, or process disclosed, or represents that its use would not infringe privately owned rights. Reference herein to any specific commercial producl, process, or service by trade name, trademark, manufacturer, or otherwise, does not necessarily constufute or imply its endorsement, recommendation, or favoring by the United States Government or any agency thereof or its contractors or subcontractors. The views and opinions of authors expressed herein do not necessarily slate or reflect those of the United States Government or any agency thereof.

This report has been reproduced from the best available copy.

Peinted in the United States of America

DISCLM. 2 CHP $(1.91)$ 
WHC-SA- -1273

DE92 003024

\section{Beneficial Uses of Radiation}

M. R. Fox

Date Published

October 1991

Speaker Bureau Presentation

Prepared for the U.S. Department of Energy Office of Environmental Restoration and

Waste Management

(2) Westinghouse $\begin{aligned} & \text { P.O. Box } 1970 \\ & \text { Hanford Company }\end{aligned}$

Hanford Operations and Engineering Contractor for the

U.S. Department of Energy under Contract DE-AC06-87RL10930

Copyright Liconss By accoptance of this articto, the publisher and/or recipient acknowlodges the U.S. Government's right to retain a nonoxdusivo, royalty-treo ticenso in and to any copyright covering this paper.

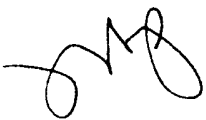

DISTRIBUTION OF THIS DOCUMENT IS UNLIMITED 


\section{BENEFICIAL USES OF RADIATION \\ by}

M. R. Fox, Ph.D.

Westinghouse Hanford Company

September 1991

\section{INTRODUCIION}

An overall decline in technical literacy within the American public has come at a time when technological advances are accelerating in the United States and around the world. This has led to a large communication gulf between the general public and the technologists. Nowhere is this more evident then with the topic of radiation.

The fusion processes that power the sun and stars have led to the existence of natural radiation throughout the universe and throughout the Earth. The molten core of the Earth, which is intimately involved with volcanism, tectonic plate movement, and earthquakes, results from the accumulated heat of decay of uranium and thorium and other isotopes in the materials of the Earth. Cosmic radiation, which fills both interstellar space and the terrestrial radiation that is so pervasive on Earth, has been a part of our environment since the beginning of Earth.

Regrettably, too few people know about these sources of radiation, the pervasiveness, amounts, and variabilities, and do not have a true understanding of the environment in which we live. Nor do many people know that radiation has been used in beneficial ways for decades around the world. While the general public does not know of the scientific applications to which radiation has been deployed, it nevertheless has benefitted tremendously from these efforts. Thanks to the well known properties of radiation, scientific ingenuity has found many uses of radiation in chemical and agricultural research, biomedical research, in the diagnoses and treatment of hundreds of types of diseases, in industrial applications, food irradiation, and many others. This paper provides a sample of the types of uses to which radiation has been used to help advance the betterment of humankind.

\section{BENEFICIAL USES}

The discussion of the beneficial uses will be outlined as follows:

- Medical uses

- Irradiation

- Food

- Medical equipment

- Agricultural uses

- Industrial uses. 


\section{STATUS OF NUCLEAR MEDICINE}

According to Stubbs and Wilson, ${ }^{1}$ there were more than 10,000,000 imaging procedures performed in the United States in 1990. These can be performed on a variety of body tissues and fluids and use a wide variety of radioactive substances and other radiation sources such as $x$ rays. These are used to perform a wide variety of analyses in determining the extent, type, and causes of a particular health problem. These can be divided into two general categories, "in vitro," meaning outside the body, and "in vivo," meaning inside the body.

These nuclear medicine techniques include the use of radioactive substances in diagnoses and therapy because they are simpler, more reliable, less costly, and less painful than earlier chemical analyses, biopsies, and exploratory surgical procedures.

"In vitro" techniques use body fluids and tissue removed from the body so the testing and diagnoses with radioactive materials can occur in a laboratory outside the body.

An example of what is being done with in vitro diagnoses is illustrative. Many hospitals give infants tests for hypothyroidism. ${ }^{2}$ Hypothyroidism can cause serious brain damage which can result in permanent mental retardation if it is not detected early (before $3 \mathrm{mo}$ ). It occurs in 1 out of 4,000 births. ${ }^{3}$ With a simple test using radioactive iodine the disease can be detected and appropriate measures taken to prevent mental retardation.

This is a highly technical part of nuclear medicine called radioimmunoassay. This area was pioneered by Dr. Rosalyn Yalow and Dr. Solomon A. Berson. Yalow won the 1977 Nobel Prize in Medicine for her efforts. Her techniques are now used in hundreds of medical laboratories around the wor?d.

The other category is "in vivo" treatment, meaning that the material, organ, or object being treated or studied is inside the body. This may involve irradiating an organ from outside the body, or it may involve the external scanning of a radioactive substance that has been placed inside the body. For example, by drinking a solution of radioactive iodine, a substance known to be selected by the thyroid gland, the gland can be made radioactive and detected by scanning (detector) equipment. In this way a doctor can obtain an image of the thyroid gland and determine the size, location, thyroid uptake, and other thyroid functions.

1"Nuclear Medicine: A State of the Art Review," James B. Stubbs and Latresia A. Wilson, Nuclear News, May 1991.

"Radioactivity in the Service of Man," Rosalyn Yalow (Nobel Laureate), Bioscience, Vol. 31, pp. 23-28, 1981.

${ }^{3}$ Dussault, J. H., P. Coulombe, and C. Laberge, 1975, "Neonatal Thyroid Screening." A1 so in pp. 221-229 in D. A. Fisher and G. N. Burrows, eds., Perinatial Thyroid Physiology and Disease, Raven Press, New York. 


\section{Diagnosis and Therapy}

There nominally are two categories of nuclear medicine, diagnostic and therapeutic. The former is the diagnosis of the problem, such as "Is the thyroid gland absorbing the appropriate amounts of iodine from the diet?" Such a diagnosis of thyroid iodine uptake is diagnostic in nature. In such, instances the iodine doses can range from tens to hundreds of microcuries. ${ }^{4}$

If the procedure is therapeutic, that is the actual treatment of a problem (such as destroying a cancerous thyroid), the iodine doses can be $100 \mathrm{mCi}$ or larger. 5 In both the diagnosis and therapy of such a problem can be performed without surgery.

\section{Additional Radiation Uses in Medicine}

There are many applications of radiation in tile world of nuclear medicine, from $x$ rays to CAT scans (Computer-Aided Tomography) and PET scans (Positron Emission Tomography), to literally millions of diagnostic and therapeutic procedures performed in the United States every year. We are much healthier as a nation as a result of the contributions of radiation technology to medicine.

${ }^{4} \mathrm{~A}$ curie is a measure of the amount of radioactive material being used. Strictly defined it is the amount of radioactive material that undergoes $3.7 \times 10$ decays per second. A millicurie is one one-thousandth of this amount and a microcurie is one one-millionth of this amount. The term curie does not provide any information about the energy of decay or of the modes of decay. Thus, a curie of ${ }^{131} \mathrm{I}$ is contained in $0.00000806 \mathrm{~g}$ of the material, and is a source of both beta and gamma radiation. A curie of ${ }^{238} \mathrm{U}$ is equivalent to 3.27 tons of uranium; it is an alpha radiation source. While trace amounts of uranium find their way into living tissue through the food chain, it cannot be used in nuclear medicine techniques since it is such a weak and inappropriate source of radiation.

${ }^{5}$ Iodine-131 has been used extensively over the years for a variety of procedures. Iodine-123 has become a preferred isotope in recent years. Both are still being used. It is instructive to compare the amount of ${ }^{131} \mathrm{I}$ in a diagnostic dose of $100 \mu \mathrm{Ci}$ to that found in Western drinking water after the Chernobyl accident. The amounts of ${ }^{131} \mathrm{I}$ from Chernobyl found in drinking water ranged widely, but a mid-range value can be assumed to be $1,000 \mathrm{pC} i$ (picocurie)/L. This is about the level found in Oregon drinking water. Simply put, the ratio between $1 \mathrm{mC} i$ and $1,000 \mathrm{pCi}$ is $1,000,000$. Thus, a person would have to drink $1,000,000 \mathrm{~L}(264,000 \mathrm{gal})$ of Oregon drinking water to receive the same amount of ${ }^{131}$ I contained in one diagnostic dose of ${ }^{131} I$. Many patients receive more than one diagnosis using ${ }^{131} \mathrm{I}$. Epidemiology studies of thyroid patients receiving such diagnostic doses show no elevated levels of thyroid cancer incidence or mortality (see, for example, "Thyroid Cancer after Diagnostic Doses of Iodine: A Retrospective Cohort Study, "LarsErik Holm et al., Journal of the National Cancer Institute, September 21 , 1988). 


\section{RADIATION DOSES TO THE PUBLIC}

Although the large benefits of nuclear medicine are clear, it represents the second largest source of radiation to the public, second only to natural sources. These other sources of radiation are well known to the scientific and medical communities but, for a varirty of reasons, are not well known to the general public.

In fact, radiation exposure studies of tens of thousands of medical patients over several decades have provided very important insight to the health effects of the applied radiation. The results of such studies are based on determining the health effects of quite large radiation doses to thousands of people over decades. In many of these studies the health effects are minimal if observable at a11.6 Of course, at higher doses such as those employed for bone marrow transplants, the health effects are very measurable.

\section{MEDICAL USES}

Some examples of the medical uses (in vivo) of radiation include:

- X ray diagnosis and therapy

- Cobalt therapy

- Radioactive injections for imaging, diagnosis, and therapy.

According to Dr. Henry Wagner, Johns Hopkins Medical Institutions, there are approximately 10 million such procedures per year in the United States.

To briefly summarize, the benefits of in vitro applications of nuclear diagnostic techniques are as follows:

- Simpler

- More sensitive and accurate

- Less costly

- Avoids intrusive surgery.

${ }^{6}$ It is not possible to 1 ist all the health studies of the radiation effects on humans. There are organizations that do retain such information. These include, but are not 1 imited to: the World Health Organization, United Nation's Scientific Committee on the Effects of Atomic Radiation. The International Council for Radiation Protection, American College of Nuclear Physicians, The Society of Nuclear Medicine, and the National Council for Radiation Protection and Measurements.

7"Viewpoint, Nuclear Medicine: The Benefits and The Risks, "Henry Wagner, M.D., Divisions of Nuclear Medicine and Radiation Health Sciences, The Johns Hopkins Medical Institutions, April 1984. 


\section{Imaging}

Imaging refers to the actual processes of viewing various organs of the body from a variety of imaging techniques. These would include the familiar $x$ ray techniques to much more sophisticated methods. Many of these other techniques include the deposition of radioactive materials in the targeted parts of the body to be viewed (imaged) for diagnosis and/or treatment. A variety of radioactive materials and sensitive scanning devices are used.

Newer imaging techniques such as Magnetic Resonance Imaging (MRI) do not require the use of radioactive materials to acquire images. Almost the entire body is accessible to imaging with these techniques. Organs such as the thyroid gland, liver, spleen, gall bladder, heart, brain, and the skeletal structures can be imaged in this way.

\section{Medical Procedures Using Radiation}

For some of the nuclear medicine procedures for therapy (treatment), elevated levels of radiation are used. In these instances there are regulatory requirements for the management and safety of the patient and the safety of hospital personnel. These include the uses of radiation detection devices and shielding for the doctors and staff.

Depending on the organ under study, most radioactive substances are administered by injections or by ingesting "cocktails." In some unusual situations radioactive gases (krypton) are inhaled to measure lung capacity and function.

Literally millions of medical tests are performed annually in the United States using radioactive materials on body tissues and fluids. They are much simpler, more accurate, more reliable, and much less costly than exploratory surgery. For example, in 1977 there were only 30,000 cases of active tuberculosis reported in the United States while in India it was estimated that more than half the population was infected with the disease. Using radioactive materials in radioimmunoassay work, new techniques have been developed. They improve the sensitivity and specificity for the early detection of the disease, improve safety of the laboratory personnel, lower the costs, increase simplicity, and permit analysis of multiple samples.

Another beneficial use of radioactive materials is in the manufacture of pacemakers for the heart. A plutonium isotope, ${ }^{238} \mathrm{Pu}$, has been used as the power source for thousands of such pacemakers which are implanted in the chests of the recipients. While the half- 1 ife of ${ }^{238} \mathrm{Pu}$ is $87 \mathrm{yr}$, suggesting indefinite use, these devices do need to be replaced at intervals of 5-10 yr.

While the public has been given the impression that radiation causes cancer at all doses and exposures, the facts are different. In fact, radiation is used beneficially in all aspects of cancer management including cancer diagnosis, staging (stage of development), therapy, and follow up.

\footnotetext{
8 "Radioactivity in the Service of Man," Rosalyn Yalow, Ph.D., Bioscience, Vol. 31, pp. 23-28, 1981.
} 
Radioactive materials that are attached to chemicals which in turn are bone seekers can highlight skeletal problems such as the presence of an arthritic or cancerous knee or ankle joint.

\section{Monoclonal Antibodies}

As the secrets of 1 ife itself begin to reveal themselves to medical research, human health and the quality of human existence will only improve. As we begin to unravel the secrets of the human genome of the replication processes, discovering the causes of genetically related diseases becomes a distinct possibility. Similarly, the treatment and even cures for such diseases become distinct possibilities. The uses of radioactive materials in such studies is proving to be invaluable in understanding these life processes.

In a relatively new area of research, monoclonal antibodies can be tagged with radioactive substances. Then, because the antibodies can be made to specifically seek cancerous cells, the cancerous cells can be irradiated within the body without the person taking massive doses to the entire body. This technique can be used for both diagnostic and therapeutic purposes. The prospects of advances in this research area are very exciting.

\section{The Role of the Fast Flux Test Facility in \\ Nuclear Medicine}

The Fast Flux Test Facility (FFTF) at the Hanford Site has served many purposes in nuclear science. These studies include advances in reactor safety, fast neutron reactor design, cladding material stability, materials technology, and the manufacture of nuclear isotopes.

As we have learned, nuclear isotopes have been used in a large number of applications. A chronic major question for users, experimenters, and medical researchers has been who will supply the isotopes, now and in the future. While there are several reactors in the United States that can supply some of the isotopes, Canada is the dominant supplier. Because the reactors being used are few, aging, and have limited neutron energy spectra, the overall performance of the suppliers remains sporadic, costly, or both.

The FFTF has the technical capabilities to manufacture many of the needed isotopes. It has the capability to manufacture isotopes in larger amounts, with the potential of reducing overall costs of the isotopes. Because it has much higher energy neutrons, it can manufacture isotopes that simply cannot be manufactured in the other reactors with low energy neutrons.

For example, ${ }^{153} \mathrm{Gd}$ is manufactured in the FFTF reactor. ${ }^{9}$ It is being used in the early detection of osteoporosis, a disease that leads first to bone thinning, and often to fractures. It effects as many as $20,000,000$ Americans. It is superior to normal $x$ ray detection of bone thinning, which cannot detect this thinning until much of the bone mass has

${ }^{9}$ I sotope Production in the FFTF by Neutron Transmutation, R. E. Schenter and M: A. Myjak, WHC-SA-0291-FP, Westinghouse Hanford Company, Richland, Washington, December 1987. 
been lost. It has the potential to positively effect the lives of millions of people. Because of the abundance of high energy neutrons at the FFTF, ${ }^{153} \mathrm{Gd}$ can be produced in greater quantities than at the other reactors.

More than 24 isotopes have been identified as being both importint to nuclear medicine and which FFTF can efficiently produce. For example, ${ }^{89} \mathrm{Sr}$ now is being used at a few medical facilities to both cure bone cancer and reduce the pain from bone cancer. Studies also show that the amount of pain-killing drugs can be significantly reduced with this technique.

\section{IRRADIATION}

Other beneficial uses of radiation occur in the field of irradiation. Irradiation connotes the exposure of the target objects to radiation and includes applications such as sterilizing medical supplies, corsumer products, and the irradiation of food. These are relatively old technologies that are quietly at work in a surprising number of industries and applications.

Most disposable medical products today are sterilized with radiation. It is a safe procedure performed without human contact in the packaging process and is done at room temperature.

The medical products industry is very well organized today and has a detailed knowledge of the various instruments required in hundreds of medical procedures. Thus, all of the instruments, sutures, sponges, and other equipment required for each procedure can be placed in plastic packages, sealed, and then sterilized with radiation. Since it is done at room temperature, the plastics containers are not damaged. A11 the equipment thus treated never touches human hands again, since doctors' hands are gloved. Thus the health of the patient and success of the surgery is enhanced by the minimization of contamination and infection with this treatment.

For some materials such as ointments and contact lens solutions, this is the much preferred method of sterilizatior since the traditional high-temperature autoclave methods would destroy the ointments and solutions.

\section{AGRICULTURE}

A major application of radioactive materials is in the world of agriculture. Such diverse areas include insect irradiation, soil research, plant genetics, animal research, fertilizer development, nitrogen fixation, and insect and pest control. In nearly all cases the techniques used involve tracer (small amounts) studies in elucidating phenomenal amounts of information in which traditional chemical techniques simply could not be used. As in medical diagnostic procedures, the reasons are that these tracer techniques are much simpler, more accurate, and more reliable. The reasons for this are that these radiation techniques can often be a thousand or a miliion times more sensitive and detectable than those provided by chemical techniques. This then provides an analytical window on biological and biochemical processes at the molecular level, which has not been available through other chemical techniques. The very understanding of 1 ife processes, by which all of mankind has benefited, has made major advances as a result of the technology application. 
Any number of studies may be undertaken, including the development of new fertilizers, nitrogen fixation with legumes, or the development of new and better pesticides, fungicides, rodenticides, etc.

\section{Insect Control}

Certain types of insect populations can be controlled by irradiation. This is not universally applicable to all insects, but in the case of certain types of fruit flies it is very effective. Male fruit flies can be sterilized with radiation without major effects on other life functions. If an orchard has a fruit fly problem, a population of sterile male fruit flies can be introduced into the wild population. Because the reproductive cycle of the fruit fly is so short, measured in weeks, the population of fruit flies can be eradicated in weeks since the males are unable to reproduce.

While the numbers of tse-tse flies in Central Africa cannot be controlled in the same way, other radiation techniques have been employed to determine its life cycle; daily, weekly, and monthly movements; and overall health status of the insect population. Such studies are invaluable in Third World countries. For example, there were 368 research contracts and agreements in 67 nations with the International Atomic Energy Agency (IAEA) in 1984.

\section{Food and Agriculture Research}

In addition to insect studies, additional applications of radioactive materials and techniques in food and agriculture include soil fertility, plant breeding and genetics, animal health and production, and food preservation.

For example, suppose one wants to improve soil fertility in a Third World nation to increase food production. A variety of minerals and nutrients must be present in the soil in a chemical form which would be available for plant growth in the climatic conditions of the particular nation. The ability of a given crop to grow and mature in a given location depends on many variables including existing nutrient levels, rainfall, daytime and nighttime temperature, and latitude (length of day and growing season).

Taking nitrogen as an example, suppose one wishes to increase the available nitrogen levels in soils. This can be done by adding appropriately selected nitrogen-bearing chemicals or through rotating desired crops with legume crops. Legumes crops (beans, peas, vetches, alfalfa, and clovers) are we11 known for their ability to remove nitrogen from the air (about $80 \%$ nitrogen) and fix it in the soil. The research questions involve which methods add the most nitrogen in the soil in a given amount of time. Even among the legumes the fixing effectiveness can range over a factor of 10 .

By using a radioactive nitrogen material $\left({ }^{15} \mathrm{~N}\right)$ as a nitrogen tracer from the legume (or fertilizer) to the soil and the crop, one can determine whether the nitrogen is being used by the plant in productive quantities, whether it remains in the soil, or has dissolved, decomposed, or blown away. Thus the choice of nitrogen addition either through fertilizer or legumes can be made. Furthermore, the optimum chemical form (for example, ammonia, urea, ammonium

${ }^{10}$ IAEA Bulletin, Vol. 27, 1985. 
salts, or nitrates, all nitrogen-bearing materials) of the nitrogen fertilizer can be developed or specified with this technique. If legumes are the preferred method of nitrogen addition, the choice of the appropriate legumes can be made with similar research.

Other applications include the large field of agricultural research in plant genetics. By using radioactive tracers to mark genetic materials within wheat, it is possible to tailor wheat hybrids for given climates, altitudes, and growing seasons. This technology was the basis of the Green Revolution in places such as India in the early 1970s, for which Dr. Norman Borlaug won the Nobel Peace Prize in 1970.

\section{FOOD IRRADIATION}

The technology of food irradiation was developed in the 1950s and 1960s and, as such, is a relatively old technology. As of 1990 there were 24 nations with unirradiated foods or food ingredients destined for commercial use.

The radiation effects on foodstuffs varies from product to product as a function of the amounts of radiation (dose). These are well understood and, as a result, there are many foodstuffs for which the process enhances the taste and texture and a few for which the foods, typically fruits, soften and turn to a mush. As with other types of irradiation, the foodstuffs do not become radioactive. For example, at relatively low doses sprout inhibition occurs in potatoes and onions, disinfesting insects occurs in fruits and grains, and there is little degradation of vitamin content in dried fruits.

At higher doses other effects can occur such as the destruction of pathological microorganisms, including spoilage microorganisms. At still higher doses food sterilization can take place. As a result of the destruction of food spoilage organisms, the shelf life of many foodstuffs is extended from weeks to sometimes years.

A huge body of international literature has corsidered many of the aspects of food irradiation. When compared with other methods of processing foods (frying, broiling, boiling), more is known about the processes involved with food irradiation than any of the others. This literature is available from most science libraries.

It comes as a surprise to many people that irradiated food is used as part of the diet for certain types of cancer patients at the Fred Hutchinson Cancer Research Center at the University of Washington. ${ }^{11}$ While some foods such as canned foods can be sterilized, many other foods are not sterile. Some can be made so ky autoclaving. Many foodstuffs are sterilized with a food irradiator at the Center. About $25 \%$ of the diet of bone marrow transplant patients is irradiated food. The reasons are that this food is very safe, and retains its taste and texture. This is very important for patients who, because of the chemotherapy and radiation therapy, have repressed immune systems and typically have alterations in their taste

11 "On the Cutting Edge of Dietetic Science," Sandra N. Aker, R.D., Nutrition Today, July/August 1984. 
perception, dry mouths, and oral and esophageal ulcerations. Food taste and texture is very impertant to people who are very ill, and who irave little desire to eat. Almost anything is a good reason not to eat.

Another benefit is shelf life extension. Unirradiated refrigerated strawberries will spoil and become inedible within a few days. The spoilage is faster at room temperature. Irradiated strawberries last significantly longer. Eventually the irradiated strawberries will spoil too, but such shelf life extensions are of keen interest in Third World countries where freezing and refrigeration are not available. It has been estimated that $25 \%$ to $30 \%$ of the food harvested world wide is lost to spoilage. In Third World countries, this number could be as high as $50 \%$.

\section{INDUSTRIAL APPLICATIONS}

The dozens of industrial applications benefit each of us everyday. Radicgraphy is one of those applications. By using a strong source of radiation, a wide variety of castings, forgings, and machined products can be examined for flaws. Other applications include non-stick coatings on cookware, permanent-press clothing, thickness and level measurements, and industrial research such as engine research.

In many such radiographs the flaws cannot be detected by visual inspection, and $x$ ray detection devices are not as sensitive in the examination of iarge metal components ( $1.3 \mathrm{Me} V$ gamma rays from a ${ }^{60} \mathrm{Co}$ source are more penetrating than $50 \mathrm{ke} V$ photons from an $x$ ray detector--an energy difference factor of 26). The technology is used, for example, in the examination of turbine blades in jet engines and in the examination of critical components for airframe manufacture.

In the construction of industrial facilities, buildings, dams, coal plants, nuclear plants, etc., such technology can be used to check for pipe and welding flaws. Portable $x$ ray machines are now available and can check the material in place, without cutting a sample to take to the laboratory. Other industrial applications are used in many clever ways. The Caterpillar Company in Peoria, Illinois, a heavy equipment manufacturer, operates a research facility that deve? aps new engines and engine components. For example, in the development of new materials for bearing surfaces, such as those between the cylinder walls, pistons, and piston rings, the material is impregnated with small amounts of radioactive material. The experimental engine is operated for various amounts of time, after which the oil is drained. Metal fragments containing the radioactive materials are separated and ana?yzed. From these measurements very precise wear patterns are established, metallurgy can be altered, designs changed, and engine lifetimes and performance exiended. The waste oil historically has been mixed with solidifying materials such as vermiculite and shipped to low-level waste sites such as those at the Hanford Site.

Another Midwest company manufactures plastic pipe. A machine tests the piping for flaws. When a flaw is detected a small sticky label containing a 1983.

\footnotetext{
12 "Food in the Nuclear Age," Raymond M. Lane, The Sun Magazine, May 22,
} 
small amount of radioactive material is attached to the piping at the flaw point. The piping then is transferred to another machine which detects the radioactive material, stops the pipe, cuts a small section of pipe out, and reattaches the two ends. All of this is done automatically. The sections of flawed pipe are packaged and shipped to low-level waste sites such as those at the Hanford Site.

In the manufacture of non-stick coated materials, the coating material undergoes a radiation treatment that increases the strength of the bond between the non-stick finish and the underlying metal. The non-stick finish does not become radioactive during the process.

Permanent-press clothing is manufactured using an irradiation process to help give the clothing a permanent press. Fundamentally the process facilitates permanent changes in the molecular structure of synthetic clothing materials.

Radioactive materials are used in a variety of ways to eliminate static, such as in the head of phonograph players and in copy machines. Static electricity can be dissipated or reduced, improving the sound of the phonograph, or improving the quality of the copy machine.

In the exploration for gas and oil several techniques are used employing radioactive materials and processes. Depending on the devices and technologies employed, different types of information can be obtained. Information about gas and oil prevalence, water content, and geochemical information can be obtained.

At the Hanford Site newer and more sensitive devices are being developed to determine the amounts and locations of natural and man-made radioactive materials. In addition, development work is in progress to extend the technology to measure chemical (nonradioactive) contaminants in burial sites, landfills, and toxic waste sites. This could have a major application to thousands of sites around the United States and the world.

Flooring durability can be extended using irradiation technology. The wood flooring material is impregnated with a preservative and then irradiated. This causes the material to undergo a cross-linking process of the molecules and thus enhances the long-term stability of the coated wood flooring. In this way the flooring lifetime is increased, the wearability is prolonged, and the appearance of newness is prolonged.

\section{ARCHEOLOGICAL RESEARCH}

All living beings, plant and animal, contain carbon, part of which is the naturally occurring radioactive ${ }^{14} \mathrm{C}$. At the time of death the living plant or animal ceases to consume carbon and serves as the beginning point in time of the relentless decay of the ${ }^{14} \mathrm{C}$ contained in the remains. By knowing the radicactive half-life of ${ }^{14} \mathrm{C}(5,730 \mathrm{yr})$, and the ${ }^{14} \mathrm{C}$ content of an ancient object, such as a skeleton, spear handle, etc., it is possible to back-calculate to the time when the object was alive. This process is called carbon dating and frequently is used in archeological research. It is 1 imited to about 5 half-lives or about 25,000 yr. Objects older than about 25,000 yr require other radioactive dating processes. 
The age of many historical objects can be determined in this way. The age of the tablecloth from King Arthur's "Roundtable" has been estimated by determining the residual amounts of radiation in the cloth. Most historians agree that the first king of England was William I, who became king in 1066 after the Battle of Hastings. No king since that time was named King Arthur, giving rise to the theory that King Arthur never existed. However, during the centuries preceding 1066, what is now England was divided into many fiefdoms, some of whose leaders were quite powerful. While the identities of many of these leaders are still not known, at least one of them did have a Roundtable, sustaining to this day the notion that someone like King Arthur did exist. Historical research continues today.

\section{LIGHTING}

The radioactive material tritium is an extraordinarily weak source of radioactivity, but it still can be put to beneficial uses. It can be used in the presence of phosphorescent materials to convert the energy into visible light. Thus, sources of 1 ight can be manufactured that require no external source of energy. Emergency exit signs are in place today in buildings and over the doors of aircraft to provide lights without requiring an external energy supply. In addition, such lights now are used to outline emergency airfields in Northern Canada and Alaska, where electrical energy would be prohibitively costly to light the runway. Tritium has a half-life of about $12 \mathrm{yr}$, so the light intensity declines to half in $12 \mathrm{yr}$. Thus, every several years the lights will need replacing. Tritium occurs naturally and is created by cosmic radiation from outer space colliding with gases in the upper atmosphere. It is also produced by man in reactors and accelerators.

\section{CONCLUSIONS}

While radiation remains a fearsome, strange, unknown aspect of our world in the 1990s, it has been studied for nearly a century around the world. As scientists discovered the properties and behavior of radiation, they also developed thousands of uses in our everyday $1 \mathrm{ife}$. Whether it is in nuclear medicine; the manufacture of paper, aluminum, non-stick pans, and permanentpress clothing; or in the development of fertilizer and pesticides, pharmaceuticals, and nuclear energy, all of these have helped to improve, not diminish, our way of 1 ife.

As in every part of our lives, there are risks to these activities, too. No matter what the activity, no matter what the public perceptions may be, there is no such thing as zero risk. However, for these activities the huge benefits outweigh the risks. The very fact that these technologies have contributed to the extension of life expectancy and improve the quality of life demonstrate that the benefits are very large indeed. 
WHC-SA-1273-FP

\section{DISTRIBUTION}

Number of Copies

ONSITE

29

Westinghouse Hanford Company

M. R. Fox (25)

Information Release Administration (3)

B2-35

Document Processing and Distribution

A2-24

L8-15 

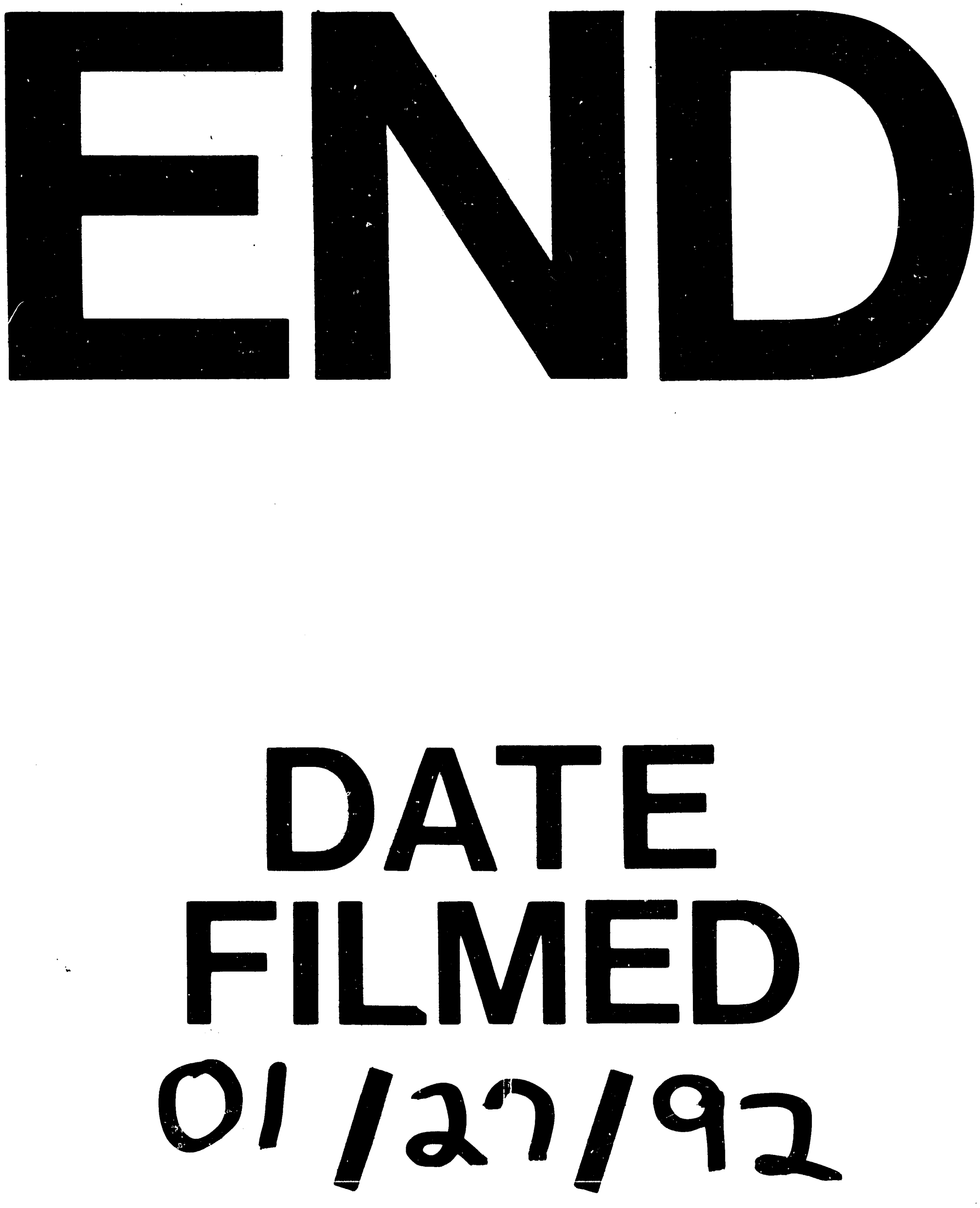

1 
